\title{
IL-1RN VNTR Polymorphism in Adult Dermatomyositis and Systemic Lupus Erythematosus
}

\author{
Zornitsa Kamenarska, ${ }^{1}$ Gyulnas Dzhebir, ${ }^{1}$ Maria Hristova, ${ }^{2}$ Alexey Savov, ${ }^{3}$ Anton Vinkov, \\ Radka Kaneva, ${ }^{1}$ Vanio Mitev, ${ }^{1}$ and Lyubomir Dourmishev ${ }^{5}$ \\ ${ }^{1}$ Molecular Medicine Center and Department of Medical Chemistry and Biochemistry, Medical University-Sofia, 2 Zdrave Street, \\ 1431 Sofia, Bulgaria \\ ${ }^{2}$ Department of Clinical Laboratory and Clinical Immunology and Department of Nephrology, Medical University-Sofia, \\ 1 Georgi Sofijski Street, 1431 Sofia, Bulgaria \\ ${ }^{3}$ National Genetic Laboratory, Maichin Dom Hospital, 2 Zdrave Street, 1431 Sofia, Bulgaria \\ ${ }^{4} 28$ Diagnostic and Consultative Center-Sofia, 1 Iliya Beshkov Street, 1592 Sofia, Bulgaria \\ ${ }^{5}$ Department of Dermatology and Venereology, Medical University-Sofia, 1 Georgi Sofijski Street, 1431 Sofia, Bulgaria
}

Correspondence should be addressed to Zornitsa Kamenarska; kamenarska@yahoo.com

Received 14 June 2014; Accepted 7 August 2014; Published 19 August 2014

Academic Editor: Elizabeth Helen Kemp

Copyright (C) 2014 Zornitsa Kamenarska et al. This is an open access article distributed under the Creative Commons Attribution License, which permits unrestricted use, distribution, and reproduction in any medium, provided the original work is properly cited.

Polymorphisms in the cytokine genes and their natural antagonists are thought to influence the predisposition to dermatomyositis (DM) and systemic lupus erythematosus (SLE). A variable number tandem repeat (VNTR) polymorphism of 86 bp in intron 2 of the interleukin-1 receptor antagonist (IL-1RN) gene leads to the existence of five different alleles which cause differences in the production of both IL-1RA (interleukin-1 receptor antagonist) and IL-1 $\beta$. The aim of this case-control study was to investigate the association between the IL-1RN VNTR polymorphism and the susceptibility to DM and SLE in Bulgarian patients. Altogether 91 patients, 55 with SLE and 36 with DM, as well as 112 unrelated healthy controls, were included in this study. Only three alleles were identified in both patients and controls ((1) four repeats, (2) two repeats, and (3) five repeats). The IL-1RN 2 allele $(P=0.02$, OR 2.5 , and $95 \%$ CI $1.2-5.4)$ and the $1 / 2+2 / 2$ genotypes were found prevalent among the SLE patients $(P=0.05$, OR 2.6, and $95 \%$ CI 1-6.3). No association was found between this polymorphism and the ACR criteria for SLE as well as with the susceptibility to DM. Our results indicate that the IL-1RN VNTR polymorphism might play a role in the susceptibility of SLE but not DM.

\section{Introduction}

Dermatomyositis (DM) and systemic lupus erythematosus (SLE) are diseases of unknown etiology. However, the dysregulation of cytokine production or action is thought to have an important role in their development [1].

Interleukin- $1 \alpha$ (IL-1 $\alpha)$ and interleukin-1 $\beta$ (IL-1 $\beta$ ) are proinflammatory cytokines which belong to the IL-1 family. The interleukin-1 receptor antagonist (IL-1RA) is a naturally occurring competitive inhibitor of IL-1. The dysregulation of IL-1 production caused by IL-1RA leads to abnormal inflammatory activity which results in subsequent tissue damage commonly observed in the pathogenesis of SLE and DM. The interleukin-1 receptor antagonist (IL-1RN) gene is polymorphic, resulting in quantitative differences in both ILIRA and IL- $1 \beta$ production. A tandem repeat sequence of 86 base pairs in length was described in intron 2 of the IL$1 R N$ gene [2]. The number of times this sequence is repeated varies from 2 to 6 . The most common is allele 1 (four repeats) followed by allele 2 ( 2 repeats). The other three alleles are rare, found in less than $1 \%$ in most populations. IL-1RN*2 allele was found associated with increased IL-1RA production in vitro [3]. The serum levels of IL-1RA were found significantly higher in lupus [4] and DM [5, 6] patients than in controls. 
TABLE 1: Demographic and clinical data.

\begin{tabular}{|c|c|c|c|c|}
\hline Disease & $\mathrm{DM}$ & & SLE & \\
\hline \multirow{2}{*}{ Demographic parameters } & Female/male & $23 / 13$ & Female/male & $46 / 9$ \\
\hline & Age, mean \pm SD years & $52 \pm 14.7$ & Age, mean \pm SD years & $40 \pm 12.4$ \\
\hline \multirow{11}{*}{ Clinical parameters } & \multirow{11}{*}{$\begin{array}{c}\text { Cutaneous disease } \\
\text { Muscle weakness } \\
\text { Elevated muscle enzymes } \\
\text { EMG findings } \\
\text { Photosensitivity } \\
\text { Autoantibodies }\end{array}$} & \multirow{11}{*}{$\begin{array}{c}27(78.8 \%) \\
28(78.8 \%) \\
19(54.6 \%) \\
20(54.6 \%) \\
21(60.6 \%) \\
9(18.2 \%)\end{array}$} & Malar rash & $34(61.8 \%)$ \\
\hline & & & Discoid rash & $11(20.0 \%)$ \\
\hline & & & Arthritis & $37(67.3 \%)$ \\
\hline & & & Oral ulcer & $4(7.3 \%)$ \\
\hline & & & Photosensitivity & $31(56.4 \%)$ \\
\hline & & & $\begin{array}{l}\text { Photosensitivity } \\
\text { Serositis }\end{array}$ & $\begin{array}{l}31(56.4 \%) \\
11(20.0 \%)\end{array}$ \\
\hline & & & Serositis & $11(20.0 \%)$ \\
\hline & & & Renal disease & $55(100 \%)$ \\
\hline & & & $\begin{array}{l}\text { Neurological disease } \\
\text { Haematological disease }\end{array}$ & $\begin{array}{l}12(22.2 \%) \\
20(36.4 \%)\end{array}$ \\
\hline & & & Immunological disease & $34(61.8 \%)$ \\
\hline & & & ANA & $39(70.9 \%)$ \\
\hline
\end{tabular}

SD: standard deviation, EMG: electromyography, and ANA: antinuclear antibodies.

The higher IL-1RA levels could serve as predictive biomarker for renal involvement in SLE [7] and positively correlated with PM/DM disease activity [8, 9].

The objective of our study was to determine whether the IL-1RN VNTR polymorphism is a risk factor for the development of adult DM and SLE in Bulgarian patients and to define its contribution to the increased risk.

\section{Materials and Methods}

2.1. Patient Population. Thirty-six patients with dermatomyositis who met the criteria of Bohan and Peter $[10,11]$ and Targoff et al. [12] and fifty-five with systemic lupus erythematosus who met the American College of Rheumatology (ACR) criteria were included in this study. Only patients with definite or probable disease were included. The clinical and demographic data are presented in Table 1. In the DM group, 23 patients were female and 13 male. The mean age was 52 with a range of $18-82$ years. In the SLE group, 46 were female and 9 male. The mean age was 40 with a range of $15-78$ years. The patients have been followed for a mean of 10 years at the Department of Dermatology and Venereology, Medical University-Sofia, at the Department of Nephrology, Medical University-Sofia, and at the Department of Nephrology, Ministry of Interior Hospital-Sofia.

The control group consisted of 112 anonymous healthy volunteers who did not show any clinical or laboratory signs of autoimmune skin diseases, as well as kinship with patients suffering from autoimmune skin diseases. They were randomly selected from the Biobank of the Molecular Medicine Center and the National Genetic Laboratory as to match the patients in age, gender, and ethnicity.

2.2. Genetic Analysis. The scientific investigation presented in this paper has been carried out in accordance with The Code of Ethics of the World Medical Association (Declaration of Helsinki) for experiments involving humans. The study was approved by the local ethics committee at the Medical University-Sofia. All participants signed an informed consent and venous blood was drawn for DNA isolation. Genomic DNA was extracted from the peripheral blood with the Chemagen DNA purification kit, using Chemagic Magnetic Separation Module I (Chemagen AG).

The analysis of IL-1RN 86 bp repeat polymorphism was performed as previously described by Tarlow et al. [2]. Standard primer pairs were used $\left(5^{\prime}\right.$-CTCAGCAACACTCCTAT; $3^{\prime}$-TCCTGGTCTGCAGGTAA). Amplification was performed under the following conditions: denaturing step at $95^{\circ} \mathrm{C}$ for 10 minutes, 35 cycles of $95^{\circ} \mathrm{C}$ for 60 seconds, $59^{\circ} \mathrm{C}$ for 60 seconds, $72^{\circ} \mathrm{C}$ for 60 seconds, and 1 cycle of extension at $72{ }^{\circ} \mathrm{C}$ for 10 minutes. The products were visualized on a $3 \%$ agarose gel stained with ethidium bromide.

2.3. Statistical Analysis. Allele and genotype frequencies were compared between DM and SLE cases and controls, using Fisher's exact test to calculate $P$ values for $2 \times 2$ tables. Where significant, data were expressed as $P$ value, odds ratios (OR) with exact $95 \%$ confidence intervals (CI).

\section{Results}

The observed allele and genotype frequencies of the IL-1RN VNTR polymorphism among the patients with DM, SLE, and the healthy controls are summarized in Table 2.

Only three alleles were detected among the Bulgarian population: 1 (four repeats), 2 (two repeats), and 3 (five repeats). The IL-1RN 2 allele $(P=0.02, \mathrm{OR} 2.5$, and $95 \%$ CI 1.2-5.4) and the $12+22$ genotypes $(P=0.05$, OR 2.6, and 95\% CI 1-6.3) were found associated with SLE (Table 2).

No association was found between that polymorphism and DM as well as with the clinical manifestations of the two diseases (Table 3).

\section{Discussion}

The majority of the studies relating IL-1RN gene polymorphisms to disease susceptibility have dealt with patients with autoimmune diseases or disorders associated with chronic inflammation [13]. 
TABLE 2: Genotype and allele frequencies of the IL-1RN VNTR polymorphism among patients with DM, SLE, and controls.

\begin{tabular}{|c|c|c|c|}
\hline Genotype & $\mathrm{DM}$ & SLE & Controls \\
\hline$N$ : number of patients & $N=36$ & $N=55$ & $N=112$ \\
\hline \multicolumn{4}{|l|}{ Genotypes } \\
\hline $1 / 1$ & $33(91.7 \%)$ & $41(74.6 \%)$ & $96(85.7 \%)$ \\
\hline $1 / 2$ & $0(0.0 \%)$ & $8(14.5 \%)$ & $9(8.0 \%)$ \\
\hline $2 / 2$ & $1(2.8 \%)$ & $4(7.3 \%)$ & $2(1.8 \%)$ \\
\hline $1 / 3$ & $2(5.6)$ & $1(1.8 \%)$ & $4(3.6 \%)$ \\
\hline $2 / 3$ & $0(0.0 \%)$ & $0(0.0 \%)$ & $1(0.9 \%)$ \\
\hline $3 / 3$ & $0(0.0 \%)$ & $1(1.8 \%)$ & $0(0.0 \%)$ \\
\hline$P$ value & $\mathrm{NS}^{*}$ & $12+22, P=0.05$ & \\
\hline \multicolumn{4}{|l|}{ Alleles } \\
\hline 1 & $68(94.4 \%)$ & $91(82.7 \%)$ & $205(91.5 \%)$ \\
\hline 2 & $2(2.8 \%)$ & $16(14.6 \%)$ & $14(6.3 \%)$ \\
\hline 3 & $2(2.8 \%)$ & $3(2.7 \%)$ & $5(2.2 \%)$ \\
\hline$P$ value & NS & $2, P=0.02$ & \\
\hline
\end{tabular}

${ }^{*}$ NS: not significant.

TABLE 3: Comparison between the genotypes and the ACR criteria for SLE.

\begin{tabular}{|c|c|c|c|c|c|c|}
\hline Genotype & $1 / 1(n=41)$ & $1 / 2(n=8)$ & $2 / 2(n=4)$ & $1 / 3(n=1)$ & $3 / 3(n=1)$ & $P$ value \\
\hline Malar rash & $28(68.3 \%)$ & $4(50.0 \%)$ & $2(50.0 \%)$ & $0(0.0 \%)$ & $0(0.0 \%)$ & $\mathrm{NS}^{*}$ \\
\hline Discoid rash & $7(17.1 \%)$ & $3(37.5 \%)$ & $1(25.0 \%)$ & $0(0.0 \%)$ & $0(0.0 \%)$ & NS \\
\hline Photosensitivity & $23(57.1 \%)$ & $5(61.5 \%)$ & $2(50.0 \%)$ & $1(100.0 \%)$ & $0(0.0 \%)$ & NS \\
\hline Oral ulcer & $3(7.3 \%)$ & $1(12.5 \%)$ & $0(0.0 \%)$ & $0(0.0 \%)$ & $0(0.0 \%)$ & NS \\
\hline Arthritis & $29(70.7 \%)$ & $5(62.5 \%)$ & $2(50.0 \%)$ & $0(0.0 \%)$ & $1(100.0 \%)$ & NS \\
\hline Serositis & $10(24.4 \%)$ & $1(12.5 \%)$ & $0(0.0 \%)$ & $0(0.0 \%)$ & $0(0.0 \%)$ & NS \\
\hline Renal disease & $41(100.0 \%)$ & $8(100.0 \%)$ & $4(100.0 \%)$ & $1(100.0 \%)$ & $1(100.0 \%)$ & NS \\
\hline Neurological disease & $10(22.9 \%)$ & $1(12.5 \%)$ & $0(0.0 \%)$ & $0(0.0 \%)$ & $1(100.0 \%)$ & NS \\
\hline Haematological disease & $15(36.6 \%)$ & $4(50.0 \%)$ & $1(25.0 \%)$ & $0(0.0 \%)$ & $0(0.0 \%)$ & NS \\
\hline Immunological disease & $24(58.3 \%)$ & $5(62.5 \%)$ & $3(75.0 \%)$ & $1(100.0 \%)$ & $1(100.0 \%)$ & NS \\
\hline \multicolumn{7}{|l|}{$\begin{array}{l}\text { (Anti-dsDNA, anti-Sm, } \\
\text { anti-phospholipid } A b \text { ) }\end{array}$} \\
\hline ANA & $29(70.7 \%)$ & $7(87.5 \%)$ & $2(50.0 \%)$ & $0(0.0 \%)$ & $1(100.0 \%)$ & NS \\
\hline
\end{tabular}

* Not significant, anti-dsDNA: antibodies to the double stranded DNA, anti-SM: anti-Smith antibodies (specific markers for SLE), and ANA: antinuclear antibodies.

The first study to correlate this polymorphism with SLE susceptibility was done on Caucasians and the carriage of IL-1RN*2 allele was reported to be associated with severity rather than susceptibility to SLE [14]. The association strengthened with extensive disease and particularly with the presence of photosensitivity and discoid skin lesions. The association of the IL1-RN*2 allele with SLE was confirmed for Japanese patients and it was again increased with photosensitivity [15]. Similarly, increased frequencies of malar rash and photosensitivity were observed among patients with IL1$\mathrm{RN}^{*} 2$ compared to patients without the allele [16]. In our study we have not observed any association between that polymorphism and ACR criteria. However, we have observed a higher frequency of the IL-1RN* 2 allele and $1 / 2+2 / 2$ genotype in patients with SLE which is in line with the results of most of the previous studies [14-18]. Our results correlate well with the results of a recent meta-analysis [19].
In Malaysia, however, the risk allele associated with SLE susceptibility was IL-1RN*1 [20] while other authors could not find any association between that polymorphism and SLE [21-23]. Quite surprisingly Mohammadoo-Khorasani et al. [24] found an association between the IL- $1 \mathrm{RN}^{*} 4$ allele and the $1 \mathrm{RN}^{*} 1 / 4$ genotype and the development of SLE in Iranian cohort. Such discrepancies could be attributed to interethnic variations [25], low frequency of the IL-1RN* 2 allele, small sample size which lacks statistical power, or influence of other polymorphisms. Furthermore, it was shown that IL1RA 2/2 was not individually associated with SLE but the combination of the Fc $\gamma$ RIIa R/R and IL-1RN 2/2 genotypes is associated with SLE in Caucasian patients [26]. The studies concerning the polymorphisms in the IL-1RN gene could have practical aspects since they might affect the response towards Anakinra, which is a recombinant form of human IL-1RA [27]. 
The frequency of the IL- $1 \mathrm{RN}^{*} 2$ allele was low among the DM patients and no statistically significant associations were found in allele and genotype distribution. Our results correlate with the results of other authors [8]. Interestingly Rider et al. [28] have found the IL-1RN* 1 allele being associated with juvenile idiopathic inflammatory myopathies (JIIM) in Caucasians, while the IL-1RN*3 allele was associated with JIIM in African-Americans.

In summary, our results indicate that IL-1RN VNTR polymorphism might play a role in the susceptibility of SLE but not DM in Bulgarian patients.

\section{Conflict of Interests}

The authors state no conflict of interests.

\section{Acknowledgments}

The genetic analysis was performed at the Molecular Medicine Center, Medical University, Sofia, supported by an infrastructure Grant DUNK01-2/2009 by the National Science Fund, Ministry of Education, Youth and Science.

\section{References}

[1] J. J. O'Shea, A. Ma, and P. Lipsky, "Cytokines and autoimmunity," Nature Reviews Immunology, vol. 2, no. 1, pp. 37-45, 2002.

[2] J. K. Tarlow, A. I. F. Blakemore, A. Lennard et al., "Polymorphism in human IL-1 receptor antagonist gene intron 2 is caused by variable numbers of an 86-bp tandem repeat," Human Genetics, vol. 91, no. 4, pp. 403-404, 1993.

[3] M. Dale and M. J. H. Nicklin, "Interleukin-1 receptor cluster: gene organization of IL1R2, IL1R1 IL1RL2 (IL-1Rrp2), IL1RL1 (T1/ST2), and IL18R1 (IL-1Rrp) on human chromosome 2q," Genomics, vol. 57, no. 1, pp. 177-179, 1999.

[4] D. M. Chang, "Interleukin-1 and interleukin-1 receptor antagonist in systemic lupus erythematosus," Immunological Investigations, vol. 26, no. 5-7, pp. 649-659, 1997.

[5] G. S. Baird and T. J. Montine, "Multiplex immunoassay analysis of cytokines in idiopathic inflammatory myopathy," Archives of Pathology \& Laboratory Medicine, vol. 132, no. 2, pp. 232-238, 2008.

[6] C. Gabay, F. Gay-Croisier, P. Roux-Lombard et al., "Elevated serum levels of interleukin-1 receptor antagonist in polymyositis/dermatomyositis: a biologic marker of disease activity with a possible role in the lack of acute-phase protein response," Arthritis and Rheumatism, vol. 37, no. 12, pp. 1744-1751, 1994.

[7] B. Brugos, E. Kiss, C. Dul et al., "Measurement of interleukin-1 receptor antagonist in patients with systemic lupus erythematosus could predict renal manifestation of the disease," Human Immunology, vol. 71, no. 9, pp. 874-877, 2010.

[8] K. Son, Y. Tomita, T. Shimizu, S. Nishinarita, S. Sawada, and T. Horie, "Abnormal IL-1 receptor antagonist production in patients with polymyositis and dermatomyositis," Internal Medicine, vol. 39, no. 2, pp. 128-135, 2000.

[9] A. M. Prieur, A. Dayer, P. Roux-Lombard, and J. M. Dayer, "Levels of cytokine inhibitors: a possible marker of disease activity in childhood dermatomyositis and polymyositis," Clinical and Experimental Rheumatology, vol. 15, no. 2, pp. 211-214, 1997.
[10] A. Bohan and J. B. Peter, "Polymyositis and dermatomyositis," The New England Journal of Medicine, vol. 292, no. 7, pp. 344347,1975

[11] A. Bohan and J. B. Peter, "Polymyositis and dermatomyositis II," The New England Journal of Medicine, vol. 292, no. 8, pp. 403407, 1975.

[12] I. N. Targoff, F. W. Miller, T. A. Medsger Jr., and C. V. Oddis, "Classification criteria for the idiopathic inflammatory myopathies," Current Opinion in Rheumatology, vol. 9, no. 6, pp. 527-535, 1997.

[13] S. S. Witkin, S. Gerber, and W. J. Ledger, "Influence of interleukin-1 receptor antagonist gene polymorphism on disease," Clinical Infectious Diseases, vol. 34, no. 2, pp. 204-209, 2002.

[14] A. I. F. Blakemore, J. K. Tarlow, M. J. Cork, C. Gordon, P. Emery, and G. W. Duff, "Interleukin-1 receptor antagonist gene polymorphism as a disease severity factor in systemic lupus erythematosus," Arthritis and Rheumatism, vol. 37, no. 9, pp. 1380-1385, 1994.

[15] H. Suzuki, Y. Matsui, and H. Kashiwagi, "Interleukin-1 receptor antagonist gene polymorphism in Japanese patients with systemic lupus erythematosus," Arthritis \& Rheumatism, vol. 40, no. 2, pp. 389-390, 1997.

[16] C.-M. Huang, M.-C. Wu, J.-Y. Wu, and F.-J. Tsai, "Interleukin1 receptor antagonist gene polymorphism in Chinese patients with systemic lupus erythematosus," Clinical Rheumatology, vol. 21, no. 3, pp. 255-257, 2002.

[17] C. G. Parks, G. S. Cooper, M. A. Dooley et al., "Systemic lupus erythematosus and genetic variation in the interleukin 1 gene cluster: a population based study in the southeastern United States," Annals of the Rheumatic Diseases, vol. 63, no. 1, pp. 9194, 2004.

[18] F. Tjernström, G. Hellmer, O. Nived, L. Truedsson, and G. Sturfelt, "Synergetic effect between interleukin-1 receptor antagonist allele (IL1RN*2) and MHC class II (DR17,DQ2) in determining susceptibility to systemic lupus erythematosus," Lupus, vol. 8, no. 2, pp. 103-108, 1999.

[19] G. G. Song, J. H. Kim, Y. H. Seo, S. J. Choi, J. D. Ji, and Y. H. Lee, "Associations between interleukin 1 polymorphisms and susceptibility to systemic lupus erythematosus: a metaanalysis," Human Immunology, vol. 75, no. 1, pp. 105-112, 2014.

[20] T. P. Lau, L. H. Lian, S. Y. Tan, and K. H. Chua, "VNTR polymorphisms of the IF-1RN gene: IL-1RN*1 allele and the susceptibility of SLE in the Malaysian population," International Journal of Biomedical and Pharmaceutical Sciences, vol. 2, no. 1, pp. 32-37, 2009.

[21] J. Heward, A. Allahabadia, C. Gordon et al., "The interleukin-1 receptor antagonist gene shows no allelic association with three autoimmune diseases," Thyroid, vol. 9, no. 6, pp. 627-628, 1999.

[22] S. D’Alfonso, M. Rampi, D. Bocchio, G. Colombo, R. ScorzaSmeraldi, and P. Momigliano-Richardi, "Systemic lupus erythematosus candidate genes in the Italian population: evidence for a significant association with interleukin-10," Arthritis \& Rheumatism, vol. 43, no. 1, pp. 120-128, 2000.

[23] V. A. Danis, M. Millington, Q. Huang, V. Hyland, and D. Grennan, "Lack of association between an interleukin-1 receptor antagonist gene polymorphism and systemic lupus erythematosus," Disease Markers, vol. 12, no. 2, pp. 135-139, 1995.

[24] M. Mohammadoo-Khorasani, S. Salimi, E. Tabatabai, M. Sandoughi, and Z. Zakeri, "Association of interleukin-1 receptor antagonist gene 86bp VNTR polymorphism with systemic 
lupus erythematosus in south east of Iran," Zahedan Journal of Research in Medical Sciences, vol. 16, no. 12, pp. 51-54, 2014.

[25] P. K. Manchanda, H. K. Bid, and R. D. Mittal, "Ethnicity greatly influences the interleukin-1 gene cluster(IL-1b promoter, exon5 and IL-1Ra) polymorphisms: a pilot study of a north Indian population," Asian Pacific Journal of Cancer Prevention, vol. 6, no. 4, pp. 541-546, 2005.

[26] A. Jönsen, A. A. Bengtsson, G. Sturfelt, and L. Truedsson, "Analysis of HLA DR, HLA DQ, C4A, FcgammaRIIa, FcgammaRIIIa, MBL, and IL-1Ra allelic variants in Caucasian systemic lupus erythematosus patients suggests an effect of the combined FcgammaRIIa R/R and IL-1Ra 2/2 genotypes on disease susceptibility.", Arthritis research \& therapy., vol. 6, no. 6, pp. R557-562, 2004.

[27] N. J. Camp, A. Cox, F. S. di Giovine, D. McCabe, W. Rich, and G. W. Duff, "Evidence of a pharmacogenomic response to interleukin-1 receptor antagonist in rheumatoid arthritis," Genes and Immunity, vol. 6, no. 6, pp. 467-471, 2005.

[28] L. G. Rider, C. M. Artlett, C. B. Foster et al., "Polymorphisms in the IL-1 receptor antagonist gene VNTR are possible risk factors for juvenile idiopathic inflammatory myopathies," Clinical \& Experimental Immunology, vol. 121, no. 1, pp. 47-52, 2000. 


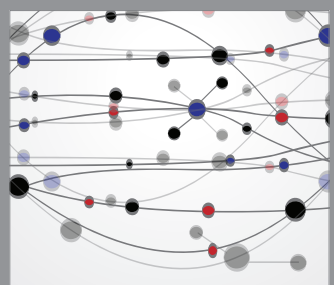

The Scientific World Journal
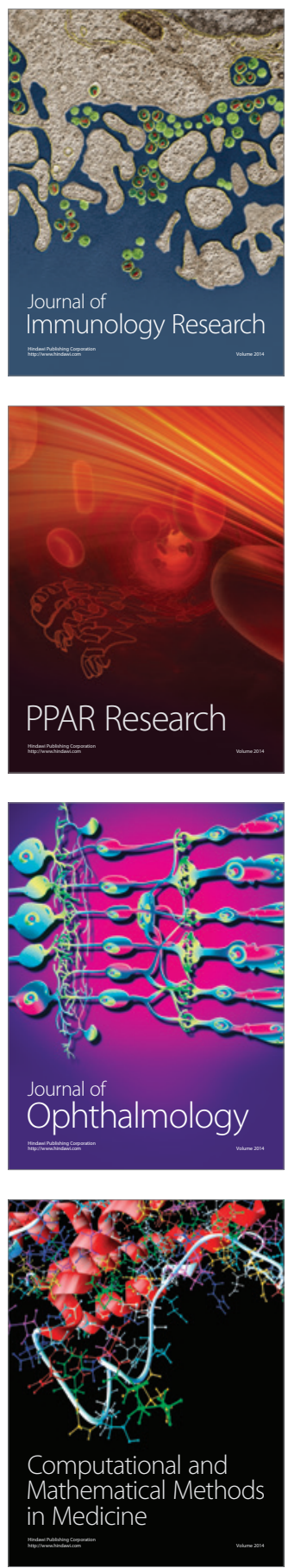

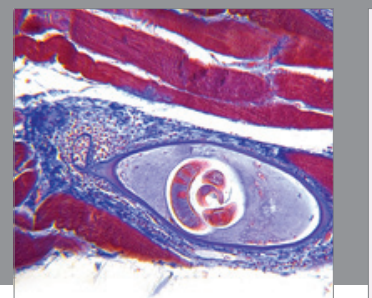

Gastroenterology

Research and Practice
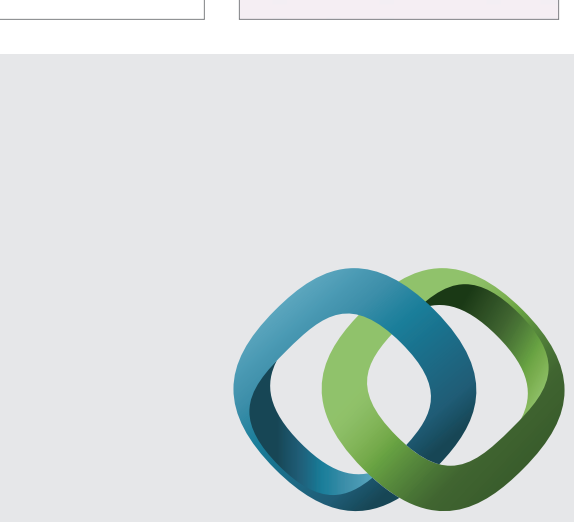

\section{Hindawi}

Submit your manuscripts at

http://www.hindawi.com
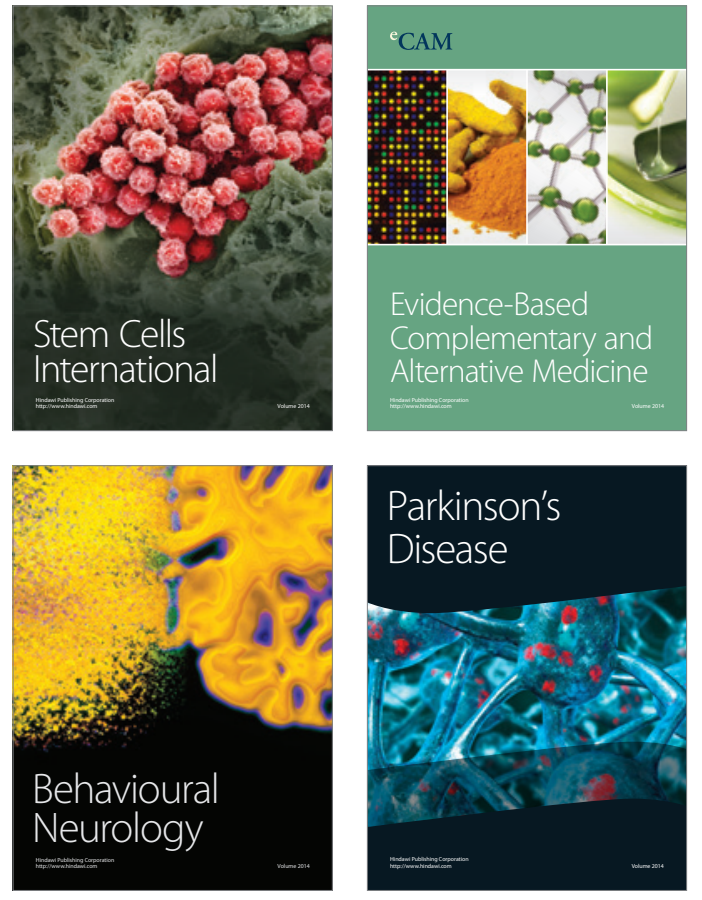
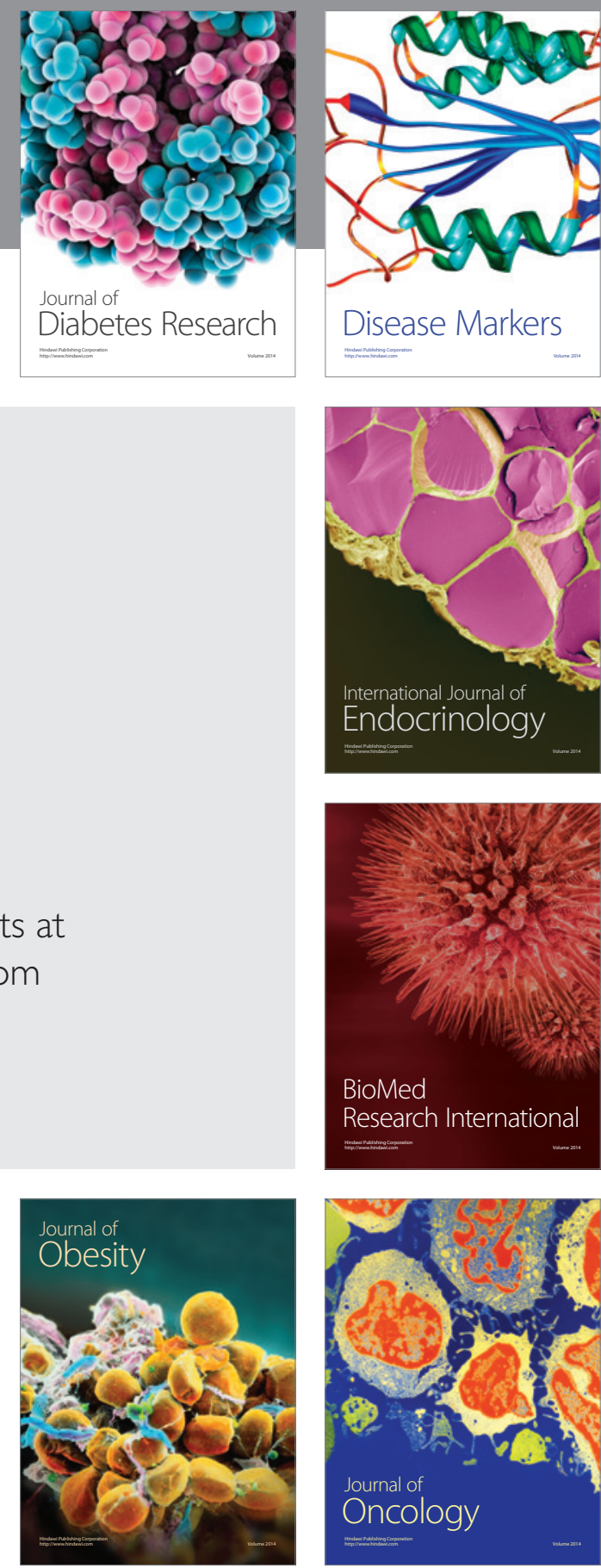

Disease Markers
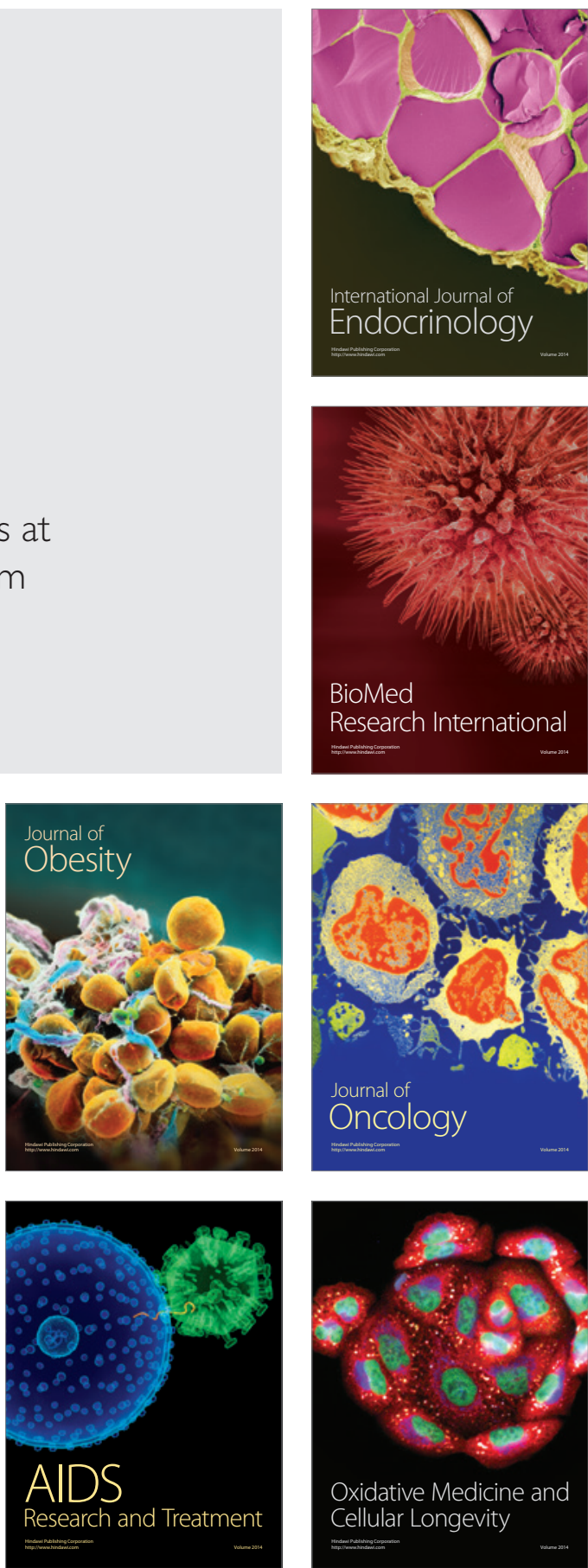